\title{
ЭКСПЕРИМЕНТАЛЬНОЕ ИССЛЕДОВАНИЕ ДИНАМИКИ ИЗМЕНЕНИЯ ЛИНЕЙНЫХ РАЗМЕРОВ АЛЬГИНАТНЫХ OTTИСКОВ
}

\section{EXPERIMENTAL STUDY OF THE DYNAMICS OF CHANGE OF LINEAR SIZES OF ALGINATE PRINTS}

V. Galonsky

N. Nurieva

V. Chernov

Yu. Kiparisov

A. Gradoboev

Summary. The article presents the results of an experimental study of the dynamics of changes in the linear dimensions of alginate impressions, depending on the time elapsed from the moment of taking the impression to the casting of the plaster model of the jaw and the storage conditions of the impression, using the example of the impression material "Ypeen". The characteristic features of the problem of shrinkage and the specifics of its manifestation in modern alginate impression materials are revealed, in comparison with the data of the classical educational literature on dental materials science.

Keywords: prosthetic dentistry, alginate impression material, shrinkage of alginate impression material, jaw impression, plaster model of the jaw.
Галонский Владислав Геннадьевич

Д.м.н., профессор, в.н.С., ФГБОУ ВО «Красноярский государственный медицинский университет имени профессора В.Ф. Войно-Ясенецкого gvg73@bk.ru

Нуриева Наталья Сергеевна Д.м.н., профессор, ФГБОУВО «Южно-уральский государственный медицинский университет» natakipa@mail.ru

Чернов Владимир Николаевич

К.м.н., дочент, ФГБОУ ВО «Красноярский государственный медицинский университет имени профессора В.Ф. Войно-Ясенецкого»

chernovortstom@mail.ru

Кипарисов Юрий Сергеевич

К.м.н., ассистент, ФГБОУ ВО «Южно-уральский государственный медицинский университет

7407704@mail.ru

Градобоев Анатолий Владимирович

Врач-стоматолог, Стоматологчческая клиника

«Гелиос»

solutiomortalis@gmail.com

Аннотация. В статье приведены результаты экспериментального исследования динамики изменения линейных размеров альгинатных оттисков, в зависимости от времени, прошедшего с момента получения оттиска до отливки гипсовой модели челюсти и условий хранения оттиска, на примере слепочного материала «Үрееп». Выявлены характерные особенности проблемы усадки и специфики её проявления у современных альгинатных оттискных материалов, в сравнении с данными классической учебной литературы по зуботехническому материаловедению.

Ключевые слова: ортопедическая стоматология, альгинатная слепочная масса, усадка альгинатного слепочного материала, оттиск челюсти, гипсовая модель челюсти.

недостатков альгинатных слепочных масс является изменение линейных размеров оттисков, зависящих от времени с момента получения оттиска до отливки гипсовой модели, а также способа хранения оттиска.

Альгинатным оттискным материалам свойственно явление синерезиса - продолжения образования поперечных связей, в результате которого вода выпо- 


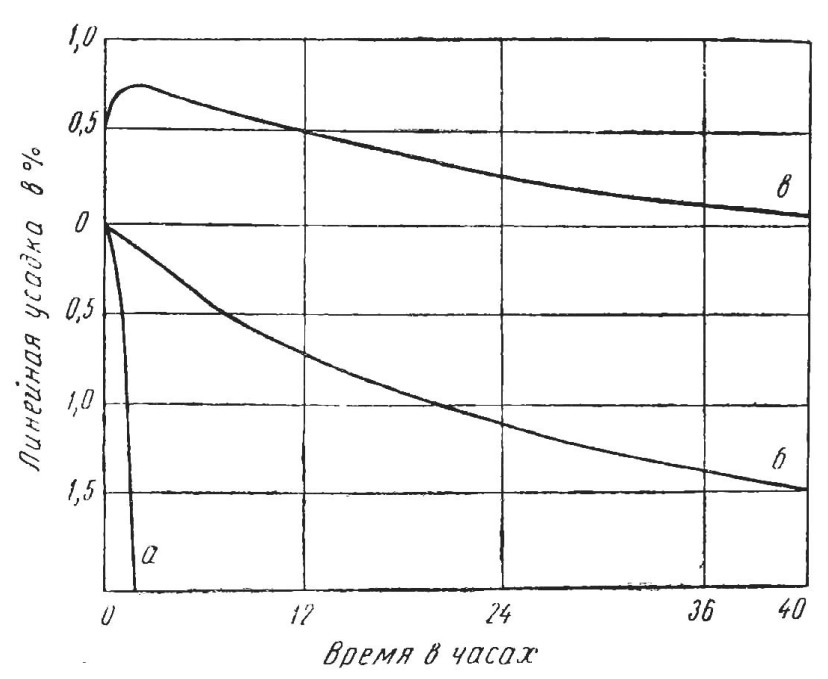

Рис. 1. Кривая усадки альгинатных материалов: а - на воздухе,

6 - при 100\% влажности в эксикаторе, в - в воде при $\mathrm{t}=37^{\circ} \mathrm{C}[1]$.

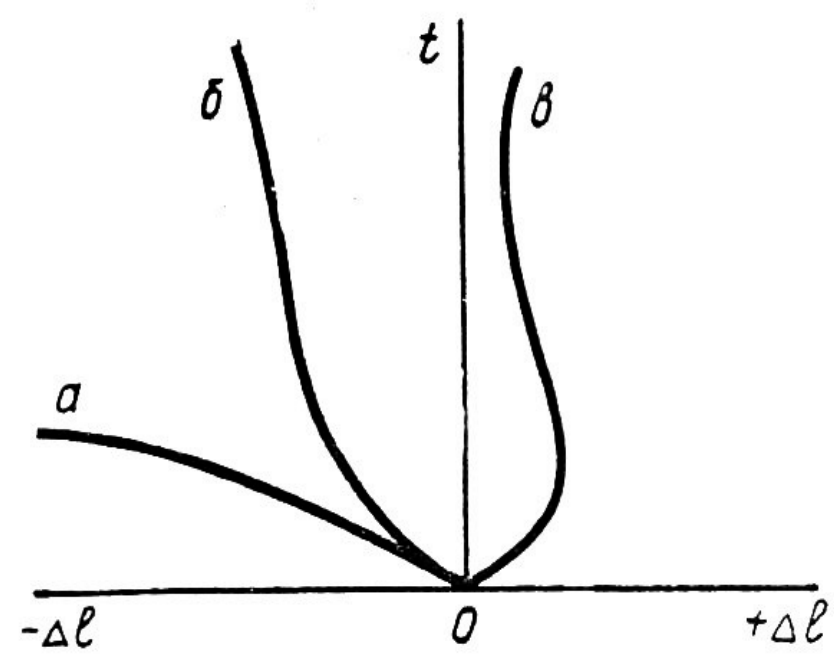

Рис. 2. Кривая усадки альгинатных материалов: а - на воздухе, 6 - при 100\% влажности в эксикаторе, в - в воде при $\mathrm{t}=37^{\circ} \mathrm{C}$ [3].

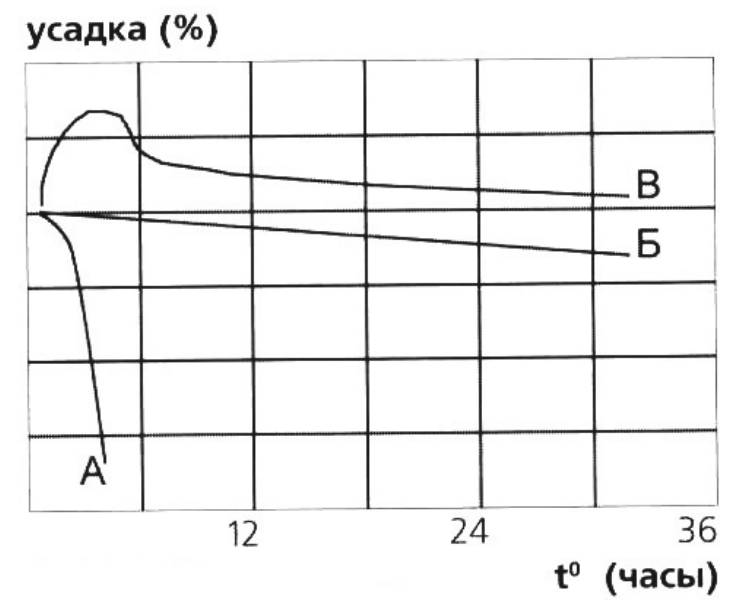

Рис. 3. Кривая усадки альгинатных материалов в зависимости от условий хранения оттиска: a - на воздухе, б - при 100\% влажности в эксикаторе, в-в воде при $t=37^{\circ} \mathrm{C}$ [5].

тевает из объёма материала на поверхность оттиска. Затем вода испаряется с поверхности и вызывает тем самым усадку оттискного материала. Другими словами синерезис - это выделение свободной жидкой фазы из альгинатного вулканита. Синерезис присущ всем оттискным материалам, изготовленным на основе агар-агара и альгината натрия. При этом процессе происходит уплощение макро молекул и сокращение оттиска в объёме. Оттиск, сохраняя прежнюю форму, уменьшается в объёме, т.е. даёт усадку. Усадка - это уменьшение линейных размеров и объёма тела при его затвердевании, охлаждении, хранении. Усадка (К) характеризуется процентом уменьшения объёма оттиска
(L) по отношению к модели $\left(\mathrm{L}_{0}\right)$ и определяется по формуле: $\mathrm{K}=\left(\mathrm{L}-\mathrm{L}_{0}\right) / \mathrm{L}_{0} \times 100 \%$. Другой причиной изменения размеров альгинатного оттиска является имбибиция разбухание оттиска при контакте с водой. В этой связи не рекомендуют хранить альгинатный оттиск в чаше с водой. Набухание - это явление, обратное усадке, вызванное поглощением влаги и приводящее к увеличению объёма оттиска.

В специальной учебной литературе $[1,3,5]$ представлены диаграммы зависимости линейной усадки альгинатных материалов от условий хранения оттиска, на примере слепочного материала «Стомальгин» 
(рис. 1-3). Интересным является факт, что при визуальном сравнительном анализе видно, что в различных руководствах приведена одна и та же диаграмма в различном дизайн исполнении, датированная различными сроками исследования. Литературный поиск позволил нам определить первоисточник опубликования данной диаграммы - монография «Материаловедение по стоматологии», авторы: М.М. Гернер, Е.Г. Аронов, А.Э. Роффе, 1964 года издания [1].

В настоящее время медицинская промышленность выпускает большую линейку представителей альгинатных оттискных материалов, различных фирм и стран производителей. Изменились и совершенствуются технологии изготовления и рецептуры выпускаемых альгинатных слепочных масс.

Исследования, посвящённые изучению проблемы динамики изменения линейных размеров современных альгинатных оттискных масс, носят единичный, разнонаправленный, эпизодический характер, использующие различные методы научного поиска $[2,4,6,7,8]$. Вместе с тем следует констатировать, что основной практической целью получения альгинатного оттиска является точность переноса информации из клиники в зуботехническую лабораторию, а именно соответствие анатомических параметров и пространственных геометрических размеров изготовленной рабочей гипсовой модели челюсти клинической ситуации в полости рта.

\section{Цель работы}

Экспериментально определить временную динамику изменения линейных размеров альгинатных масс, на примере слепочного материала «Ypeen», на основе антропометрических измерений гипсовых моделей челюстей.

\section{ЗаАачи исслеАования}

1. Определить временную динамику изменения линейных размеров альгинатного оттиска, хранящегося на открытом воздухе при комнатной температуре (от 20 до $25^{\circ} \mathrm{C}$ ).

2. Определить временную динамику изменения линейных размеров альгинатного оттиска, хранящегося в герметично закрытом полиэтиленовом пакете, при комнатной температуре (от 20 до $\left.25^{\circ} \mathrm{C}\right)$.

3. Определить временную динамику изменения линейных размеров альгинатного оттиска, хранящегося в сосуде с холодной водопроводной водой (от 10 до $15^{\circ} \mathrm{C}$ ).

4. Выполнить сравнительную оценку динамики изменения линейных размеров альгинатных от- тисков в зависимости от временных параметров с момента получения оттиска до отливки гипсовой модели и условий хранения оттиска.

\section{Материалы и метомы}

Используемые материалы: 1) Альгинатный слепочный стоматологический материал «Ypeen» - производитель ф. Spofa Dental (Чехия), используемый для получения оттиска; 2) Медицинский гипс «Волма» (Россия), используемый для отливки гипсовых моделей челюстей.

Измерительный прибор: Штангенциркуль «ШЦЦ Ермак» первого класса точности, с цифровым отсчётным устройством с точностью измерения 0,01 мм, используемый для антропометрического измерения сагиттальных и трансверзальных параметров гипсовых моделей челюстей.

Условия выполнения эксперимента: 1) Замешивание слепочной массы и получение альгинатного оттиска осуществляли в соответствии с инструкцией к слепочному материалу и рекомендациями производителя, с применением прилагающихся мерных емкостей для дозирования порошка слепочной массы и воды для её замешивания; 2) Экспериментальные оттиски получали у одного и того же добровольца с интактным верхним зубным рядом; 3) Отливку гипсовых моделей осуществляли в соответствии с традиционной методикой, предварительно убрав излишки воды с поверхности оттиска воздушной струёй пустера для профилактики искажения поверхности получаемой гипсовой модели.

Серии экспериментального получения гипсовых моделей челюстей:

Эталоном для стартового вычисления динамики изменений линейных размеров альгинатных оттисков являлась гипсовая модель, отлитая непосредственно после получения альгинатного оттиска. Эксперимент предусматривал три разных серии, в зависимости от условий хранения оттиска перед отливкой гипсовой модели челюсти: 1) Хранение альгинатного оттиска на открытом воздухе при комнатной температуре (от 20 до $\left.25^{\circ} \mathrm{C}\right)$; 2) Хранение альгинатного оттиска в герметично закрытом полиэтиленовом пакете, при комнатной температуре (от 20 до $25^{\circ} \mathrm{C}$ ); 3) Хранение альгинатного оттиска в сосуде с холодной водопроводной водой (от 10 до $15^{\circ} \mathrm{C}$ ).

Общие временные критерии для всех трёх серий эксперимента отливки опытных гипсовых моделей челюстей предусматривали временной диапазон, включающий отливку моделей через 15 мин, 30 мин, 45 мин, 


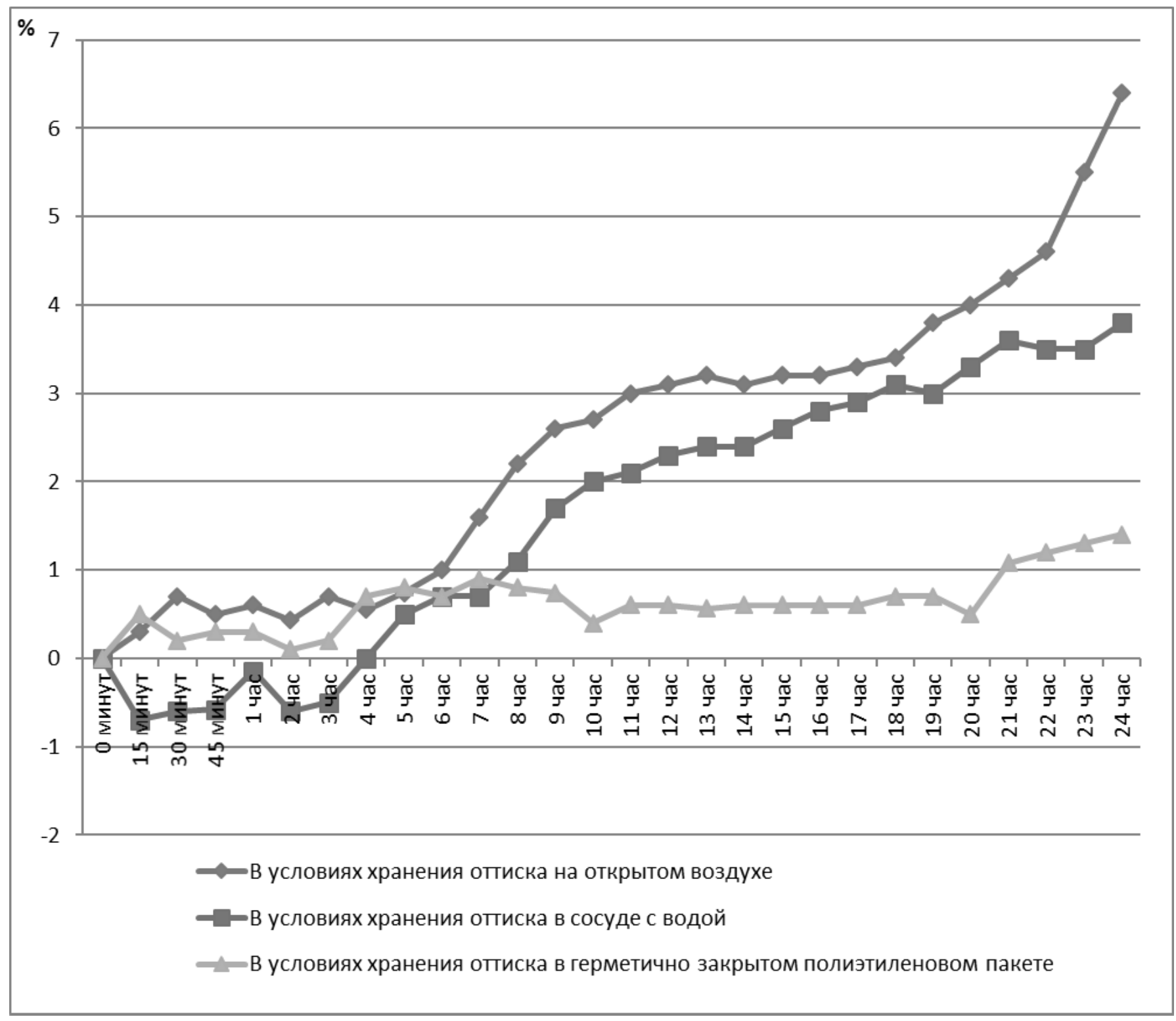

Рис. 4. Временная динамика изменения линейных размеров альгинатных оттисков, хранящихся в различных условиях (на примере слепочного материала «Ypeen»).

1 час и так далее с последовательным шагом в 1 час до отметки 24 часа. В результате эксперимента в общем количестве, с учётом эталонной модели и трёх серий отливки экспериментальных моделей, у одного и того же добровольца (волонтёра) было получено 82 альгинатных оттиска и отлито 82 гипсовых модели челюстей, антропометрическое измерение которых позволило судить о динамике изменения линейных размеров альгинатных оттисков.

Протокол антропометрического измерения полученных в эксперименте гипсовых моделей челюстей заключался в следующем: 1) Измерение трансверзальных размеров челюсти по Пону (1907) между первыми пре- молярами (измерительные точки - центр межбугорковых фиссур зубов 1.4 и 2.4); 2) Измерение трансверзальных размеров челюсти по Пону (1907) между первыми молярами (измерительные точки - переднее углубление продольной фиссуры зубов 1.6 и 2.6); 3) Измерение сагиттальных размеров челюсти - от точки межзубного контакта верхних центральных резцов (зубов 1.1 и 2.1) с вестибулярной стороны до линии соединяющей дистальные поверхности зубов 1.7 и 2.7, соответственно траектории проекции серединного нёбного шва.

Динамику изменения линейных размеров альгинатных оттисков определяли на основании изменения антропометрических размеров каждой из полученных 
в эксперименте гипсовых моделей челюстей методом математического вычисления по формуле:

$$
\mathrm{M}=\frac{\left(\mathrm{S}+\mathrm{T}_{1}+\mathrm{T}_{2}\right)-\left(\mathrm{s}+\mathrm{t}_{1}+\mathrm{t}_{2}\right)}{\left(\mathrm{s}+\mathrm{t}_{1}+\mathrm{t}_{2}\right)}
$$

где $M$ - величина изменения линейных размеров альгинатного оттиска, в \%;

$\left(s+t_{1}+t_{2}\right)$ - сумма результатов антропометрического измерения эталонной гипсовой модели челюсти в сагиттальном направлении $(s)$, трансверсальном направлении между премолярными точками $\left(t_{1}\right)$ и молярными точками $\left(t_{2}\right)$;

$\left(S+T_{1}+T_{2}\right)$ - сумма результатов антропометрического измерения экспериментальной гипсовой модели челюсти в сагиттальном направлении $(S)$, трансверсальном направлении между премолярными точками $\left(T_{1}\right)$ и молярными точками $\left(T_{2}\right)$.

\section{Результаты и их обсужАение}

Результаты экспериментального изучения временной динамики изменения линейных размеров альгинатных оттисков (на примере слепочного материала «Ypeen»), хранящихся в различных условиях, на основании измерения сагиттальных и трансверзальных антропометрических размеров отлитых по ним гипсовых моделей челюстей, относительно эталонной модели, представлены на рис. 4.

Анализируя представленные на рис. 4 данные, можно констатировать, что полученные результаты имеют ряд отличительных особенностей относительно ранее выполненных исследований, посвящённых данной проблеме. Экспериментально установлено, что явления усадки альгинатного оттискного материала начинают проявляться уже через 15 мин после получения оттиска. При этом, анализируя данные графика, можно заключить, что во всех трёх сериях эксперимента достоверно визуализируются две фазы усадки. Первая из них характеризуется незначительными изменениями геометрических размеров оттисков до 1\% в сторону уменьшения или увеличения линейных размеров, длящаяся до 6 часов хранения. Вторая фаза характеризуется ярко выраженными усадочными явлениями слепочного материала до максимальной величины 6,4\% по истечении 24 часов.

Временная динамика изменения линейных размеров альгинатного оттиска, хранящегося на открытом воздухе при комнатной температуре (от 20 до $25^{\circ} \mathrm{C}$ ), показала наиболее выраженные проявления усадки слепочного материала, в сравнении с двумя другими альтернативными способами хранения оттисков. В пер- вой фазе усадки прослеживается варьирование данного показателя с превышением на 0,2-0,4\% в сравнении с оттисками, хранящимися в герметично закрытом полиэтиленовом пакете, в аналогичном промежутке времени. Во второй фазе усадки увеличение исследуемого показателя происходит постепенно, возрастая в каждом последующем сроке наблюдения, достигая максимальной величины 6,4\% по истечении 24 часов эксперимента.

Временная динамика изменения линейных размеров альгинатного оттиска, хранящегося в сосуде с холодной водопроводной водой (при температуре в диапазоне от 10 до $\left.15{ }^{\circ} \mathrm{C}\right)$, показала, что в первой фазе происходит изменение геометрических размеров оттисков в сторону увеличения до 1\%, за счёт явления имбибиции - разбухания оттиска при контакте с водой. То есть выявлялось явление, обратное усадке,- набухание. Вместе с тем следует констатировать, что данное явление наблюдалось только в первой фазе усадки, при этом сагиттальные и трансверзальные размеры экспериментальной гипсовой модели челюсти, полученной по оттиску, хранившемуся 4 часа в воде, соответствовали эталонной. При дальнейшем хранении оттиска в воде явление набухания сменялось постепенно увеличивающимся со временем явлением усадки, достигающим к концу первой фазы 0,7-1\%, а к окончанию второй фазы, по истечении 24 часов, максимальной величины - 3,8\%. То есть оттиск, хранящийся в воде на начальном этапе, незначительно увеличивался в размерах, а в дальнейшем давал ощутимую общую усадку - на $1 \frac{1}{2}$ меньшую по величине, в сравнении с оттисками, хранящимися на воздухе в тот же промежуток времени.

Временная динамика изменения линейных размеров альгинатного оттиска, хранящегося в герметично закрытом полиэтиленовом пакете, при комнатной температуре (от 20 до $25^{\circ} \mathrm{C}$ ) показала наиболее стабильные результаты. Проявления усадки при данном способе хранения наименьшие в сравнении с двумя вышеописанными. В первой фазе усадки они составляли в среднем 0,1-0,3\%, во второй фазе - 0,5-0,7\%.

\section{Зак^ючение}

Сравнительная оценка динамики изменения линейных размеров альгинатных оттисков в зависимости от временных параметров с момента получения оттиска до отливки гипсовой модели и условий хранения оттиска, позволяет заключить, что при использовании любого из исследованных способов хранения альгинатный оттиск даёт изменения геометрических размеров уже через 15 мин после его получения, которые проявляются в изменении сагиттальных и трансвер- 
зальных размеров отлитых гипсовых моделей челюстей. При этом усадка альгинатного оттискного материала на металлической перфорированной слепочной ложке проявляется в различном направлении: в сторону перфорированных бортов ложек, механически удерживающих слепочную массу; в сторону наиболее массивных участков оттиска и т.д. В данной связи отличия гипсовых моделей челюстей от оригинала протезного ложа могут проявляться по-разному, чаще всего в виде протрузионного разворота зубных рядов в вестибулярную сторону, с изменением сагиттальных и трансверсальных размеров зубных рядов, продольных и поперечных размеров зубов и деформации окклюзионной поверхности.

\section{ВывО $\triangle \mathrm{b}$}

1. Экспериментальное изучение эволюционных процессов - процессов постепенного развития, приводящих к последовательным количественным изменениям, формирующим качественные изменения современных альгинатных оттискных материалов, на примере слепочного материала «Yреen», позволяет констатировать ярко выраженную нестабильность геометрических параметров оттисков, зависящую от момента их получения до отливки рабочей гипсовой модели челюсти.
2. Известные методы хранения альгинатных оттисков (в герметично закрытом полиэтиленовом пакете, на открытом воздухе при комнатной температуре от 20 до $25^{\circ} \mathrm{C}$ или в сосуде с холодной водой) являются неадекватными. Их клиническое применение формирует одну из основополагающих проблем в клинике ортопедической стоматологии и ортодонтии - несоответствие входящей информации о состоянии клинической картины в полости рта, поступающей на основании переданного из клиники оттиска в зуботехническую лабораторию, что в совокупности способствует формированию конфликтных ситуаций в процессе лечения и по его окончании.

3. Изготовление рабочих гипсовых моделей челюстей по альгинатным оттискам следует выполнять непосредственно после их получения и выведения из полости рта, что диктует необходимым овладевание данной практической манипуляцией всех врачей соответствующих специальностей, несущих персональную ответственность за конечный результат ортопедического и ортодонтического лечения каждого конкретного пациента.

Конфликт интересов. Авторы декларируют отсутствие явных и потенциальных конфликтов интересов, связанных с публикацией настоящей статьи.

\section{ЛИТЕРАТУРА}

1. Гернер М.М. Материаловедение по стоматологии / М.М. Гернер, Е.Г. Аронов, А.Э. Рофе.— М.: Гос. изд-во мед. лит., 1963. — 256 с.

2. Гринёва Т.В. Альгинатные слепочные материалы. Свойства и применение / Т.В. Гринёва, Е.И. Ипполитова // Новое в стоматологии для зубных техников. - 2000. - № 2. - С. 34-36.

3. Дойников А.И. Зуботехническое материаловедение / А.И. Дойников, В.Д. Синицин. — М.: Медицина, 1981. — 208 c.

4. Ефремян Г.М. Усадка оттискных материалов / Г.М. Ефремян, Д.С. Цокарев, А.Е. Штерен // Сб. Актуальные вопросы стоматологии. Материалы межрегиональной заочной научно-практической конференции с международным участием, посвящённой 85-летию проф. В.Ю. Миликевича, 2017. - С. 136140.

5. Оттискные материалы и технологии их применения / А.В. Цимбалистов, С.И. Козицина, Е.Д. Жидких, И.В. Войтяцкая. - СПб.: СПб. институт стоматологии, 2001. - 96 с.

6. Полонейчик Н.М. Характеристика изменений линейных размеров альгинатных оттискных материалов с использованием оптического метода исследования / Н.М. Полонейчик, В.И. Кирилова // Сб. Инновации в стоматологии. Материалы VI съезда стоматологов Беларуси (Минск, 25-26 октября 2012 г.). - Минск: Филиал № 10 АО «Красная звезда», 2012. - С. 203-204.

7. Сравнительная оценка альгинатных слепочных материалов / А.В. Годзь, В.А. Парунов, Е.И. Ипполитова, Т.В. Гринёва // Проблемы нейростоматологии и стоматологии. - 1998. - № 2.- С. 15-17.

8. Техника измерения усадки стоматологических оттисков / С.Д. Арутюнов, З.В. Сакиева, С.А. Муслов и др. // Российский стоматологический журнал.2015. — Т., № 1.— C. 11-13.

\footnotetext{
๑ Галонский Владислав Геннадьевич ( gvg73@bk.ru ), Нуриева Наталья Сергеевна ( natakipa@mail.ru ), Чернов Владимир Николаевич ( chernovortstom@mail.ru ), Кипарисов Юрий Сергеевич ( 7407704@mail.ru ), Градобоев Анатолий Владимирович ( solutiomortalis@gmail.com ). Журнал «Современная наука: актуальные проблемы теории и практики»
} 